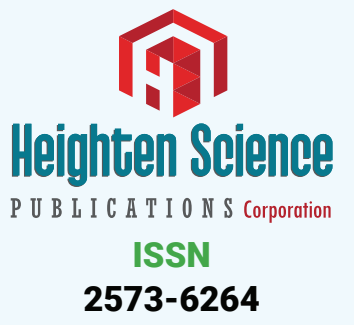

*Address for Correspondence: Jean-Michel Brismée, 2 Texas Tech University Health Sciences Center, Lubbock, TX, USA, Email: jm.brismee@ttuhsc.edu

Submitted: 03 June 2017

Approved: 14 July 2017

Published: 17 July 2017

Copyright: @ 2017 Gerke D, et al. This is an open access article distributed under the Creative Commons Attribution License, which permits unrestricted use, distribution, and reproduction in any medium, provided the original work is properly cited.

Keywords: Stress fracture; Irish dance; plantar foot
Case Report

\section{First Metatarsal Stress Fracture of a pre-adolescent female Irish dancer with Medial Plantar Foot Pain: A Case Report}

\author{
Dale Gerke ${ }^{1}$ and Jean-Michel Brismée ${ }^{2 *}$ \\ ${ }^{1}$ Concordia University Wisconsin, Mequon, WI, USA \\ ${ }^{2}$ Texas Tech University Health Sciences Center, Lubbock, TX, USA
}

\section{ABSTRACT}

Background and Purpose: Injuries for the pre-adolescent female Irish Dancer (FID) are not well recognized. The purpose of this case study is to report imaging assisted diagnosis and management of atypical medial and plantar foot pain (MPFP) in an 8-year-old FID.

Description: The patient presented with chief complaint of diffuse left MPFP. The patient was initially evaluated by a Physical Therapist for persistent foot pain. The patient experienced minimal pain in non-weightbearing (NWB). Pain intensified in weightbearing (WB) escalating with a heel raise. The patient experienced pain with resistance testing, ankle passive range of motion (PROM) and first metatarsophalangeal joint (MTPJ) PROM. Diffuse tenderness with palpation over the medial column of the left foot was noted. The patient was unable to complete single leg dynamic activity on the left foot. There was suspicion for a metatarsal stress fracture (MSF). Radiographs were ordered and read as negative. The patient was treated with immobilization in a walking boot, WB as tolerated and relative rest including cessation of dance. The patient returned for re-evaluation 2 weeks after reporting no change in symptoms. Magnetic Resonance Imaging (MRI) was then ordered.

Outcome: Results of the MRI identified 2 stress fractures in the first metatarsal. The treatment plan changed to NWB status with immobilization for an additional 6 weeks. The patient returned to full WB status and participated in all dance activity 15 weeks after the initial presentation to the Physician and 27 weeks after the initial onset of MPFP.

Discussion/Conclusion: In this pre-adolescent FID, the presentation of MPFP can be misinterpreted as a soft tissue injury. It is important to consider the diagnosis of first MSF in a pre-adolescent FID to allow appropriate management.

\title{
INTRODUCTION
}

Irish dance is a common activity for pre-adolescent youth with intense training leading to overuse injuries. Professional Irish dancers frequently experience plantar foot pain related to plantar fasciitis or stress fractures of the second Metatarsal, third Metatarsal or sesamoids. Injuries for the pre-adolescent female Irish Dancer (FID) are not well recognized. A recent study of pre-professional dancers identified that females are more susceptible to time away from dancing related to injury. Furthermore, the most severe injuries that kept dancers away from their sport were stress fractures [1]. Like many athletic participants, injury can lead to time away from participation and future pathologies such as early osteoarthritis [2]. Several authors have identified the injury rate of pre-professional dancers to be similar to other sports [2]. However, there is very little information related to the reporting of dance injuries. Ballet has a higher incidence of reported dance injuries, but little information is available for competitive 
pre-adolescent FID. Therefore, the purpose of this case study is to report imaging assisted diagnosis and management of atypical medial and plantar foot pain (MPFP) in an 8 year-old FID.

\section{DESCRIPTION}

An 8 year-old female Irish Dancer presented to the clinic with a 12-week history of chronic left plantar foot pain. Initially, the plantar foot pain was intermittent and did not limit participation in any age appropriate activities including dance. Eventually, the intensity, frequency and duration of MPFP increased with the patient independently limiting school-related activities at recess and gym class. The initial Lower Extremity Functional Scale (LEFS) score was 51/80 (64\%).

The initial physical examination demonstrated 7/10 pain on a Numerical pain scale with all ankle active motions except dorsiflexion. Strength testing at the ankle was limited secondary to pain with all resistance testing except ankle dorsiflexion. Passive range of motion of the first and second metatarsals were painful in all directions. Palpation was diffusely painful throughout the medial column on the plantar surface. The patient was able to walk on their bilateral heels. However, the patient was unable to walk on toes or perform a single leg balance attempt on the left foot secondary to pain.

Due to high suspicion for stress fracture, the patient was referred to a Physician for consideration of medical imaging. Plain film radiographs were ordered and read as negative. Early treatment included immobilization in a walking boot with weight bearing as tolerated. Similarly, the patient observed relative rest including cessation of all dance activity. Physical Therapy was attempted to maintain ankle and foot motion, gentle isometric strengthening and massage. Physical Therapy interventions were not well tolerated. Therefore, the patient was again referred to the Physician due to a lack of progress over the first 3 visits. The patient then received an MRI of the left foot secondary to persistent plantar foot pain despite immobilization and relative rest. Patient consent to use the information in a case report was obtained.

\section{RESULTS/DISCUSSION}

To our knowledge, this is the first documented case report of an 8 year old child with exercise induced first MSF, initially misdiagnosed due to negative radiographic imaging. The results of the Philips Intera MRI System with image quality at 1.5 Tesla demonstrated multiple stress fractures in the First Metatarsal (Figures 1,2). Management of the fractures were modified to non-weight bearing status and continuous immobilization for an additional 6 weeks.

First metatarsal stress fractures are rare secondary to the overall size of the bone. In contrast, the second metatarsal frequently experiences a stress fracture [3] because it is the longest and thinnest metatarsal creating a larger bending moment [4]. First metatarsal stress fractures occur very rarely as ninety percent of all metatarsal stress fractures occur in second, third or fourth matatarsals [5]. The rare occurrence of first metatarsal stress fractures can make it challenging for the clinician to include a first metatarsal stress fracture in the differential diagnosis. In this case, it was likely the multiple fractures in the first metatarsal also created a more diffuse nature of the symptoms.

Metatarsal Stress Fractures (MSF) are most common in the $2^{\text {nd }}$ and $3^{\text {rd }}$ Metatarsals [6] making up 51\% and 32\% of all MSF, respectively. Intrinsic risk factors for MSF have also been noted in dancers including malalignment or amenorrhea. A challenge in the pre-adolescent population is minimal information related to the immature musculoskeletal system especially in the absence of menarche. Noon et al. [7] reported the average age of injury for FID was 13 years and most fractures occurring 


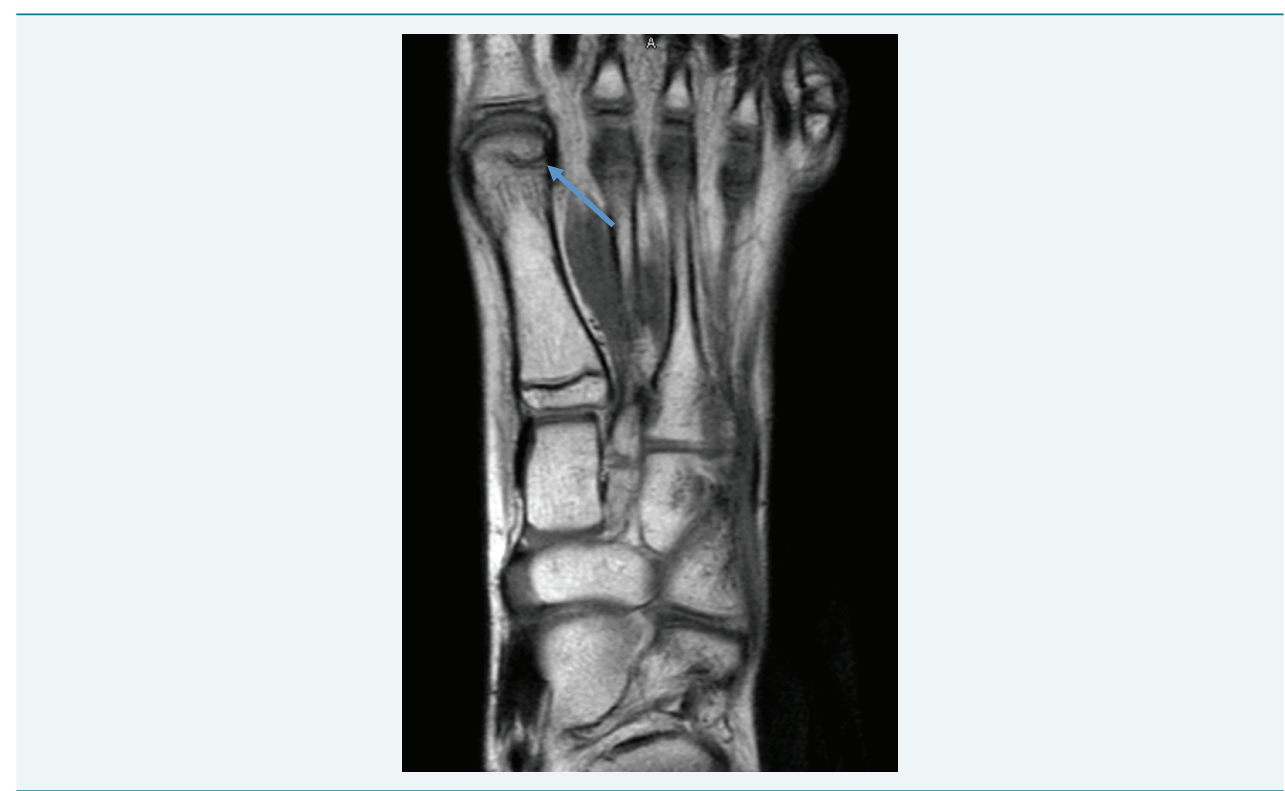

Figure 1: T1 weighted MRI showing a stress fracture at the distal aspect of First Metatarsal.

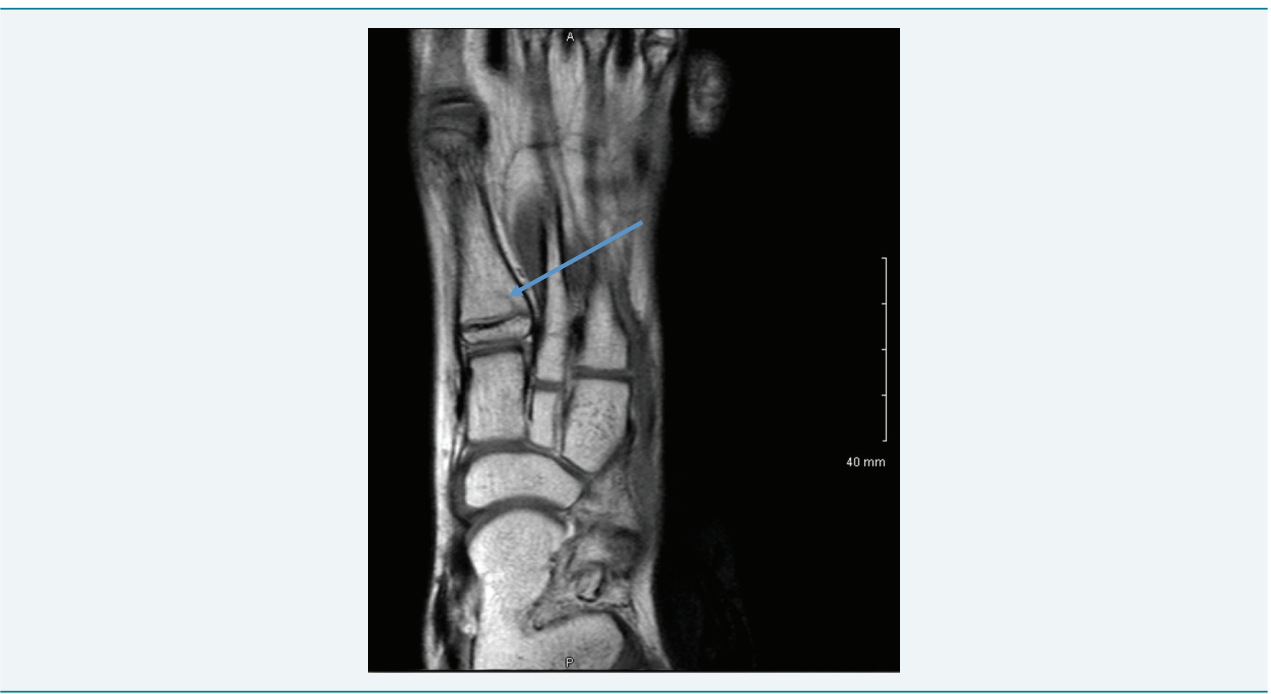

Figure 2: T1 weighted MRI showing a stress fracture at the proximal aspect of First Metatarsal.

in the sesamoids. Stress fractures are common in young female athletes with heavy consideration of the female athlete triad in young athletes [4]. According to Lee, (2017), stress fractures were among the most severe injuries limiting participation in pre-professional dancers [8].

A diagnostic challenge in the pre-adolescent population is that radiographs are frequently negative [6] unless there is a cortical defect. A risk factor for stress fractures can be a prior history of stress fractures, increased training time [7] and menstrual irregularities $[5,9]$. However, this dancer had no prior orthopedic related injuries. Early recognition of MSF is important to guide interventions, but reliance on radiographs for diagnosis can also lead to a delay in appropriate management. Greater suspicion of a stress fracture may lead to earlier investigation with MRI. Additionally, diagnostic delay can cause the young dancer to continue dancing in pain progressing the problem or preventing an eventual rapid return to dancing [9]. Early recognition of stress fractures in children identified with a fracture line are treated earlier and the potential for complete recovery has been shown to be more rapid than when the diagnosis is delayed [10]. The patient in our study returned to dance participation 15 weeks after the initial Physician visit. 
Management of the patient in the first stage of rehabilitation included hip strengthening, desensitization techniques, and ankle AROM during the nonweight bearing period. The next stage of rehabilitation included implementation of manual therapy techniques to reduce pain and improve range of motion at the first metatarsophalangeal joint. Additionally, pelvic ring stabilizing exercises and low level weight bearing exercises were initiated. The last phase of rehabilitation progressed to balance exercises, plyometric exercises and intrinsic foot strengthening. The dancer was able to complete a Y-balance test with less than a $4 \mathrm{~cm}$ difference in the anterior reach. All interventions were performed by a single physical therapist over 18 sessions. The pain level in the left foot was reported at $0 / 10$ and the LEFS score was $75 / 80$ (94\%) when the patient returned to dance activities.

Future studies should consider identifying risk factors for young, competitive Irish Dancers so that appropriate injury prevention programs can be utilized. Similarly, earlier recognition of stress fractures will also lead to better follow-up which will help identify ideal outcomes for these patients.

\section{CONCLUSION}

Injuries to pre-adolescent female dancers are not well documented. Stress fractures are common because the intensity of the dancing is high. First metatarsal stress fractures are rare, but need to be considered in the differential diagnosis of MPFP. Early recognition of stress fractures can help return the FID to dance activities with less time away from competition.

\section{REFERENCES}

1. McGuinness D, Doody C. The injuries of competitive Irish dancers. J Dance Med Science. 2006; 10: 35-39. Ref.: https://goo.gl/i5MDba

2. Kenny SJ, Whittaker JL, Emery CA. Risk factors for musculoskeletal injury in preprofessional dancers: a systematic review. Br J Sports Med. 2016; 50: 997-1003. Ref.: https://goo.gl/UiWjbV

3. Mandell JC, Khurana B, Smith SE. Stress fractures of the foot and ankle, part 2: site specific etiology. Imaging, and treatment, and differential diagnosis. Skeletal Radiol. 2017; Ref.: https://goo.gl/3T9pkX

4. Wall J, Feller JF. Imaging of Stress Fractures in Runners. Clin Sports Med. 2006; 25: 763-780. Ref.: https://goo.gl/CDuvhV

5. Weinfeld SB, Haddad SL, Myerson MS. Metatarsal stress fractures. Clin Sports Medicine. 1997; 16: 319-338.

6. Umnas HR. Imaging Sports medicine injuries of the foot and toes. Clin Sports Med. 2006; 25: 763780. Ref.: https://goo.gl/wD5cav

7. Noon M, Hoch AZ, McNamara L, Schimke J. Injury patterns in female Irish dancers. PM R. 2010; 2: 1030-1034. Ref.: https://goo.gl/5gQEap

8. Lee L, Reid D, Caldwell J, Palmer P. Injury incidence, dance exposure and the use of the movement competency screen to identify variables associated with injury in full-time pre-professional dancers. Int J Sports Phys Ther. 2017; 12: 352-370. Ref.: https://goo.gl/r4bZNG

9. Albisetti W, Perugia D, DeBartolomeo O, Tagliabue L, Camerucci E, et al. Stress fractures of the base of the metatarsal in trainee ballet dancers. Int Orthop. 2010; 34: 51-55. Ref.: https://goo.gl/5krUK5

10. Niemeyer $P$, Weinberg A, Schmitt $H$, Kreuz PC, Ewerbeck $V$, et al. Stress fractures in the juvenile skeletal system. Int J Sports Med. 2006; 27: 242-249. Ref.: https://goo.gl/xs1BzF

11. Bennell K, Brukner P. Preventing and managing stress fractures in athletes. Phys Ther Sport. 2005; 6: 171-180. Ref.: https://goo.gl/zjz7sP

12. Boden BP, Osbahr DC. High-risk stress fractures: evaluation and treatment. J Am Acad Orthop Surg 2000; 8: 344-353. Ref.: https://goo.gl/WZYDfG

13. Mayer SW, Joyner PW, Almekinders LC, Parekh SG. Stress fractures of the foot and ankle in athletes. Sports Health. 2013; 6: 481-491. Ref.: https://goo.gl/3gUhFU 
14. O'Halloran E, Vioreanu M, Padinjarathala B. Between the jigs and the reels. Bilateral metatarsal phalangeal stress fractures in a young Irish dancer. Clin J Sport Med. 2011; 21: 454-455. Ref.: https://goo.gl/xCxHbv

15. Walls RJ, Brennan SA, Hodnet P, O'Byrne JM, Eustace SJ, et al. Overuse ankle injuries in professional Irish dancers. Foot Ankle Surg. 2010; 6: 45-49. Ref.: https://goo.gl/HPmE8h

16. Wild CY, Grealish A, Hopper D. Lower limb and trunk biomechanics after fatigue in competitive female Irish dancers. J Athl Train. 2017; 52: 1-6. Ref.: https://goo.gl/M7VSYB 